\title{
Molecular-pathological prognostic factors of gastric cancer: a review
}

\author{
Wataru Yasui, Naohide Oue, Phyu Phyu Aung, Shunji Matsumura, Mariko Shutoh, \\ and Hirofumi NaKayama \\ Department of Molecular Pathology, Hiroshima University Graduate School of Biomedical Sciences, 1-2-3 Kasumi, Minami-ku, \\ Hiroshima 734-8551, Japan
}

\begin{abstract}
Invasion and metastasis are critical determinants of cancer morbidity. Genes and molecules participating in these steps must be regarded as potential prognostic factors. Growth factors and their receptors, cell-cycle regulators, cell-adhesion molecules and matrix-degrading enzymes are those to be used as prognostic factors, including epidermal growth factor (EGF), EGF receptor, K-sam, HER-2, interleukin (IL)-8, vascular endothelial growth factor (VEGF), cyclin E, p27, Ecadherin, CD44v6, matrix metalloproteinase-1 (MMP-1), and tissue inhibitor of matrix metalloproteinase-1 (TIMP-1). Alterations in epigenetics, such as aberrant DNA methylation and histone modification that are, in part, associated with the tumor progression of gastric cancer, can be candidate prognostic factors. The number of methylated genes may serve as a marker of tumor progression. Genetic polymorphism not only affects cancer susceptibility but also influences malignant phenotype; examples include single-nucleotide polymorphism in the HER-2 and MMP-9 genes. Comprehensive gene expression analyses are useful to search for novel genes related to invasion and metastasis and potential prognostic factors. Serial analysis of gene expression (SAGE) has identified several these genes, such as $C D H 17, A P O E, F U S, C O L 1 A 1$, COL1A2, GW112, and MIA. Overexpression of MIA is found to be associated with poor prognosis. Microarray analysis has great potential for identifying the characteristics of individual cancers, from the view point of gene expression profiles. A combination of these examinations can not only foretell a patient's prognosis but can also give information directly connected with personalized cancer medicine and prevention.
\end{abstract}

Key words Prognostic factor - Gastric cancer - Epigenetics · Genetic polymorphism - Serial analysis of gene expression

Offprint requests to: $\mathrm{W}$. Yasui

Received: January 24, 2005 / Accepted: February 18, 2005

\section{Introduction}

Advances in diagnosis and treatment have offered excellent long-term survival for early gastric cancer; however, the prognosis of advanced cancer still remains poor. Cancer morbidity results in large part from metastases, and a majority of patients with advanced cancer die due to complications by metastases, not by the primary tumor. Integrated research in molecular pathology over the past 15 years has uncovered the molecular mechanism of invasion and metastasis in gastric cancer [1-5]. To produce a metastasis, tumor cells must complete a multistep progression through a series of sequential and selective events [6]. The metastatic process consists of tumor cell detachment, local invasion, motility, angiogenesis, vessel invasion, survival in the circulation, adhesion to endothelial cells, extravasation, and regrowth in different organs (Fig. 1). In each step, causative molecules have been identified; these include cell-adhesion molecules, various growth factors, matrix degradation enzymes, and motility factors, and most of these can be regarded as prognostic factors. Recent advances in genomic science have enabled us to uncover the detailed molecular mechanism of stomach carcinogenesis and its progression. A better knowledge of the molecular bases will lead to new paradigms and possible improvements in diagnostics and therapeutics. Analyses of gene expression profiles and genetic polymorphisms are approaches to identify novel prognostic factors. This review describes changes in genes and molecules to be used as prognostic factors of gastric cancer, and their application in the clinical setting.

\section{Classical prognostic factors}

Genes and molecules participating in proliferation, invasion, and metastasis, such as growth factors and their receptors, cell-cycle regulators, cell-adhesion mol- 


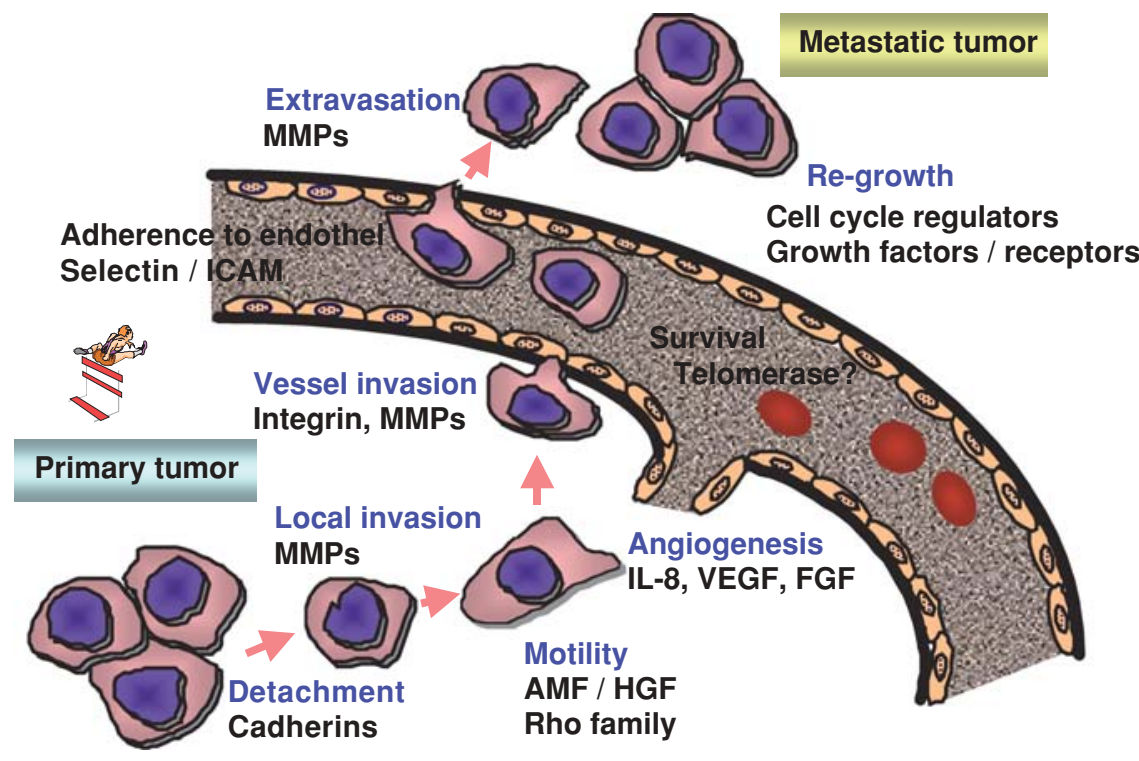

Fig. 1. Molecular mechanism of hematogenous metastasis. MMPs, matrix metalloproteinases; IL, interleukin; $V E G F$, vascular endothelial growth factor; $F G F$, fibroblast growth factor; $A M F$, autocrine motility factor; $H G F$, hepatocyte growth factor; ICAM, intercellular adhesion molecule

Table 1. Molecular and genetic markers related to invasion, metastasis, and prognosis

\begin{tabular}{ll}
\hline Category & \multicolumn{1}{c}{ Molecular and genetic markers } \\
\hline Growth factor & EGF, TGF-alpha, EGF receptor, c-met, K-sam, HER-2, IL-8, VEGF \\
Cell-cycle regulator & Cyclin E, p27, p53, RB, CDC25B \\
Telomere & POT1 \\
Cell adhesion molecules & E-cadherin, dysadherin, CD44v6, CD44v9 \\
Matrix metalloproteinase & MMP-1, MMP-2, MT1-MMP, TIMP-1 \\
\hline
\end{tabular}

ecules, and matrix-degrading enzymes are good prognostic factors (Table 1).

\section{Growth factors, cytokines, and angiogenic factors}

Gastric cancer cells express a variety of growth factors and their receptors to make autocrine and paracrine loops $[1,2,4]$. These factors induce not only cell growth but also extracellular matrix degradation and angiogenesis for tumor invasion and proliferation. The simultaneous expression of epidermal growth factor (EGF)/ transforming growth factor (TGF)-alpha and EGF receptor correlates with deep invasion, advanced stage, and poor prognosis. The amplification of the c-met encoding receptor for hepatocyte growth factor is frequently associated with poor prognosis of gastric cancer, especially of scirrhous type. The amplification and overexpression of the K-sam and $H E R-2 / c$-erbB2 genes may be prognostic factors for well-differentiated type and poorly differentiated or scirrhous type, respectively [2,7]. Angiogenesis is a prerequisite for tumor growth and metastasis that depends on the production of angiogenic factors by host and tumor cells. Neova- scularization enhances the growth of primary tumors and provides an avenue for hematogenous metastasis. Gastric cancer cells produce various angiogenic factors, including vascular endothelial growth factor (VEGF), interleukin (IL)-8, basic fibroblast growth factor (bFGF), and platelet-derived endothelial cell growth factor (PD-ECGF) [8-10]. Because increasing vascularity correlates with lymph-node metastasis, hepatic metastasis, and poor prognosis, all of these may be candidate prognostic factors of gastric cancer. In fact, the prognosis in patients with tumors displaying high IL-8 and VEGF expression levels is significantly poorer than that in patients whose tumors with low expression levels [11].

\section{Cell-cycle regulators}

Cell-cycle checkpoints are regulatory pathways that control cell-cycle transitions, DNA replication, and chromosome segregation. Abnormalities in cell-cycle regulators are involved in stomach carcinogenesis through genomic instability and unbridled cell proliferation $[2,4,12]$. The cyclin $\mathrm{E}$ gene is amplified in $15 \%-$ 
$20 \%$ of gastric cancers, and the overexpression of cyclin E correlates with the aggressiveness of the cancer. Reduction in the expression of $\mathrm{p} 27^{\mathrm{Kip} 1}$, a cyclin-dependent kinase (CDK) inhibitor, is frequently associated with advanced gastric cancers, and the reduced expression of p27 ${ }^{\mathrm{Kip} 1}$ also significantly correlates with deep invasion and lymph-node metastasis. It has been shown that reduced p27 expression is a negative prognostic factor for patients with a cyclin E-positive-tumor [13]. Aberrant expression (reduced or overexpression) of the p16 gene is frequently found in gastric cancers, but does not correlate with patients' prognosis [14]. An important regulator at the G1/S checkpoint is retinoblastoma (RB) protein. RB expression is lower in lymph-node metastasis than in the corresponding primary tumors [15]. Univariate and multivariate survival analyses have revealed that reduced expression of $\mathrm{RB}$ is associated with worse overall survival. The product of the tumor suppressor gene, $p 53$, is multifunctional and participates in cell-cycle regulation partly through p21 induction. Although nearly 200 articles concerning p53 abnormality in gastric cancer in relation to patients' prognoses have been published, the prognostic impact remains controversial. Recent reports indicate that abnormal expression of $p 53$ significantly affects cumulative survival and that $p 53$ status may also influence response to chemotherapy [16,17]. The overexpression of checkpoint kinase 1 (Chk1) and Chk2, DNA damage-activated kinases involved at the $\mathrm{G} 2 / \mathrm{M}$ checkpoint, is associated with $p 53$ mutations, but has no prognostic impact. The overexpression of CDC25B is found in $70 \%$ of gastric cancers, and is associated with invasion and metastasis.

\section{Genetic instability}

Dysfunction of the DNA mismatch repair system is responsible for microsatellite instability (MSI). MSI causes accumulation of genetic alterations, and participates in the pathogenesis of sporadic gastric carcinomas, in addition to hereditary nonpolyposis colorectal cancer (HNPCC) [4]. The frequency of MSI is estimated to be around $30 \%$ in gastric cancers, with an especially high frequency in well-differentiated gastric carcinoma of foveolar phenotype with papillary morphology. Many reports have demonstrated the relation between MSI and cancer multiplicity [18-20]. All show that the frequency of MSI is significantly higher in patients with multiple primary cancers. Therefore, the detection of MSI may serve as a good indicator for the assessment of a second cancer risk in the same patient. There have been many studies examining the relation between MSI and the prognosis of patients' with gastric cancer [21-24]. Most studies have shown that MSI is associated with less aggressive behavior and favorable survival, while some indicated no prognostic impact.

\section{Telomeres and telomerase}

The maintenance of telomeres by telomerase activation induces cellular immortalization and participates in carcinogenesis [25]. Strong telomerase activity associated with human telomerase reverse transcriptase ( $h T E R T)$ expression is present in a majority of gastric carcinomas, regardless of tumor staging $[4,15,26]$. Protection of telomeres 1 (POT1), a telomere end-binding protein, is proposed not only to cap telomeres but also to recruit telomerase to the ends of chromosomes [27]. POT1 expression levels are significantly higher in gastric cancer of advanced stage, and POT1 downregulation is frequently observed in gastric cancers of early stage, suggesting that POT1 may be a marker of high-grade malignancy [27].

\section{Cell-adhesion molecules}

Cell-adhesion molecules may function as tumor suppressors. E-cadherin plays a major role in epithelial tissues to regulate morphogenesis and inhibit cell infiltration. Multivariate analyses have revealed that reduced E-cadherin expression is an independent prognostic factor [28]. Dysadherin, a cancer-associated cell-membrane glycoprotein, downregulates E-cadherin expression and promotes metastasis [28]. Patients with both dysadherin positivity and reduced E-cadherin have the worst prognosis, although dysadherin is not an independent prognostic factor [28]. Soluble fragment of Ecadherin is known to be increased in the sera of cancer patients [29]. Serum soluble E-cadherin is a valid prognostic marker for gastric cancer, and a high concentration predicts palliative/conservative treatment and extensive tumor invasion [29]. CD44 is an important cell-adhesion molecule, and its variants, generated by alternative splicing, modulate cell-to-cell interaction, movement, and finally metastatic potential. There is a significant survival advantage in patients with low expression of CD44 sharing variant exon 6 (CD44v6) compared with those with high expression [30]. Furthermore, The serum level of soluble CD44v6 is a prognostic indicator in patients with poorly differentiated type gastric cancer [31]. The expression of CD44v9 is associated not only with tumor invasion, metastasis, and advanced stage but also with the tumor-recurrence mortality of gastric cancer $[4,32]$.

\section{Matrix metalloproteinases (MMPs)}

A balance of activities between matrix-degrading enzymes and their inhibitors is important in determining tumor invasion and metastasis. Among various MMPs, The expression of MMP-7, also known as matrilysin, is correlated with vessel invasion and both lymphatic and hematogenous metastases [33], while the prognosis of 
patients with MMP-1-positive tumors is significantly worse than that of patients with MMP-1-negative tumors [34]. Membrane-type 1 (MT-1) MMP is an activator of MMP-2. MT1-MMP expression is an independent factor influencing both tumor invasion and metastasis. Although MT1-MMP is not an independent prognostic factor, patients with tumors having a high tumor/normal $(\mathrm{T} / \mathrm{N})$ ratio of MT1-MMP show a significantly poorer prognosis than those with a low ratio [35]. Tissue inhibitors of MMP (TIMPs) inhibit tumor invasion through the inactivation of MMPs. In a multivariate analysis, the $\mathrm{T} / \mathrm{N}$ ratio of TIMP-1 was shown to be an independent factor influencing tumor invasion and the second most important factor in determining the prognosis of the patients [36].

\section{Epigenetic alterations as prognostic factors}

Among the various epigenetic alterations that lead to modified gene expression, the most important are believed to be DNA methylation and chromatin remodeling by histone modification [5]. Some aberrant epigenetics modifications are associated with tumor progression of gastric cancer, and could be candidate prognostic factors.

\section{Histone acetylation}

Inactivation of chromatin by histone deacetylation is involved in the transcriptional repression of several tumor suppressor genes, including $p 21^{\text {WAFI/CIPI }}$. Hypoacetylation of histones $\mathrm{H} 3$ and $\mathrm{H} 4$ in the $p 21^{\text {WAFI/Cip } 1}$ promoter region is observed in more than $50 \%$ of gastric cancer tissues by chromatin immunoprecipitation [37]. By using anti-acetylated histone antibody, the global acetylation status of histone can be analyzed immunohistochemically in tissue specimens of gastric cancer [5]. The level of acetylated histone H4 expression is reduced in $70 \%$ of gastric cancers in comparison with non-neoplastic mucosa, indicating global hypoacetylation in gastric cancer. Reduced expression of acetylated histone $\mathrm{H} 4$ correlated well with advanced tumor stage, deep tumor invasion, and lymph-node metastasis. Thus, low levels of global histone acetylation may serve as a marker of high-grade malignancy. In fact, trichostatin $\mathrm{A}$, a histone deacetylase inhibitor, induces growth arrest and apoptosis and suppresses the invasion of gastric cancer cells [5,38].

\section{Accumulation of DNA methylation in multiple genes}

The hypermethylation of $\mathrm{CpG}$ islands is associated with the silencing of various tumor suppressor genes and participates in tumorigenesis. These genes include p16 MTSIIINK4A $^{2}$ CDH1 (E-cadherin), hMLH1, RAR-beta, RUNX3, MGMT, TSP1, HLTF, RIZ1, and SOCS-1 [4,39-45]. Among these, DNA methylation of CDH1, RAR-beta, and SOCS-1 is significantly associated with tumor invasion and metastasis. Gastric cancers frequently have the $\mathrm{CpG}$ island methylator phenotype (CIMP), which may be an important pathway involved in stomach carcinogenesis [46]. However, no significant association has been found between CIMP and tumor progression. We analyzed DNA methylation in 12 tumor-related genes ( $h M L H 1, M G M T, p 16, C D H 1$, RAR-beta, HLTF, RIZ1, TM, FLNs, LOX, HRASLS, $H A N D 1)$ in gastric cancers and found that the average number of methylated genes per tumor was about five. We then divided cancers into two groups; cancers with five or more methylated genes (high-methylation group) and those with four or fewer methylated genes. The high-methylation group was found more frequently in stage III and stage IV cancers than in stages I and II. Thus, the number of methylated genes may serve as a molecular marker of tumor progression, although the prognostic implication remains to be elucidated.

\section{Genetic polymorphism as a prognostic factor}

Genetic polymorphism is an important determinant of endogenous causes of cancer. An overview of genetic susceptibility and gastric cancer risk has been described by Gonzalez et al. [47]. Representative genetic polymorphisms modifying gastric cancer risk include IL1beta (IL1B), IL-1 receptor antagonist (IL1RN), and $\mathrm{N}$-acetyltransferase (NAT1). Regarding the relation between genetic polymorphisms of tumor-related genes and gastric cancer, we have performed case-control and case-case studies, in about 500 subjects [48-52]. A single-nucleotide polymorphism (SNP; A > G, Ile > $\mathrm{Val}$ ) is present in the transmembrane domain of the $H E R-2 / \mathrm{c}-e r b B 2$ gene, while there are SNPs in the promoter regions of the EGF (61 A/G), E-cadherin (-160 C/A), MMP-1 (-1607 1G/2G), and MMP-9 (-1562 C/T) genes. All the promoter SNPs described above are known to influence the respective gene expression. As shown in Table 2, our case-control study showed that SNPs of the HER-2, EGF, and E-cadherin genes significantly affected gastric cancer risk, while the genotypes of the $M M P-1$ and $M M P-9$ genes did not differ between the gastric cancer cases and the controls. Among the gastric cancer patients, the genotypes of the HER-2, Ecadherin, and $M M P-9$ genes were associated with tumor invasion, metastasis, or stage grouping. As for the MMP-1 gene, a significant association was detected only with histological differentiation. Therefore, SNPs of the HER-2, E-cadherin, and MMP-9 genes could serve as a predictor of risk for a malignant phenotype. The prog- 
Table 2. Single-nucleotide polymorphisms of five genes and relation to relation to cancer risk and progression

\begin{tabular}{|c|c|c|c|c|c|}
\hline \multirow[b]{2}{*}{ Gene (substitution) } & \multirow[b]{2}{*}{ Case-control } & \multicolumn{4}{|c|}{ Gastric cancer cases $^{\mathrm{d}}$} \\
\hline & & $\mathrm{T}$ grade & $\mathrm{N}$ grade & Stage & Histology \\
\hline $\begin{array}{l}H E R-2 / c-e r b B 2 \\
\text { (Ile655Val) }\end{array}$ & $\begin{array}{c}P=0.033^{\mathrm{a}} \\
\text { OR } 3.25^{\mathrm{b}} \\
(1.08-9.76)^{\mathrm{c}}\end{array}$ & $\begin{array}{c}P=0.026 \\
2.18 \\
(1.11-4.30)\end{array}$ & $\begin{array}{c}P=0.001 \\
2.18 \\
(1.11-4.30)\end{array}$ & $\begin{array}{c}P<0.001 \\
3.49 \\
(1.84-6.63)\end{array}$ & $\begin{array}{c}P=0.068 \\
1.83 \\
(0.90-3.72)\end{array}$ \\
\hline $\begin{array}{l}E G F \\
(61 \mathrm{~A} / \mathrm{G})\end{array}$ & $\begin{array}{c}P=0.012 \\
\text { OR } 0.56 \\
(0.35-0.89)\end{array}$ & $\begin{array}{c}P=0.043 \\
1.80 \\
(0.98-3.30)\end{array}$ & $\begin{array}{c}P=0.035 \\
1.98 \\
(1.01-3.89)\end{array}$ & $\begin{array}{c}P=0.008 \\
2.26 \\
(1.21-4.22)\end{array}$ & $\begin{array}{c}P=0.034 \\
1.89 \\
(1.04-3.45)\end{array}$ \\
\hline $\begin{array}{l}\text { E-cadherin } \\
(-160 \mathrm{C} / \mathrm{A})\end{array}$ & $\begin{array}{c}P=0.003 \\
\text { OR } 2.68 \\
(1.50-4.79)\end{array}$ & $\begin{array}{c}P=0.001 \\
4.95 \\
(2.02-12.1)\end{array}$ & $\begin{array}{c}P=0.010 \\
2.86 \\
(1.28-6.36)\end{array}$ & $\begin{array}{c}P=0.004 \\
3.41 \\
(1.46-7.94)\end{array}$ & $\begin{array}{c}P=0.029 \\
2.31 \\
(1.02-5.24)\end{array}$ \\
\hline $\begin{array}{l}M M P-1 \\
(-16071 \mathrm{G} / 2 \mathrm{G})\end{array}$ & $\begin{array}{c}P=0.571 \\
\text { OR } 0.83 \\
(0.43-1.59)\end{array}$ & $\begin{array}{c}P=0.904 \\
1.02 \\
(0.24-4.35)\end{array}$ & $\begin{array}{c}P=0.919 \\
1.14 \\
(0.16-8.13)\end{array}$ & $\begin{array}{c}P=0.271 \\
3.04 \\
(0.83-11.2)\end{array}$ & $\begin{array}{c}P=0.03 \\
3.56 \\
(1.15-11.1)\end{array}$ \\
\hline $\begin{array}{l}M M P-9 \\
(-1562 \mathrm{C} / \mathrm{T})\end{array}$ & $\begin{array}{c}P=0.223 \\
\text { OR } 0.765 \\
(0.49-1.18)\end{array}$ & $\begin{array}{c}P=0.03 \\
2.61 \\
(1.07-6.34)\end{array}$ & $\begin{array}{c}P=0.23 \\
1.54 \\
(0.76-3.10)\end{array}$ & $\begin{array}{c}P=0.02 \\
2.26 \\
(1.12-4.55)\end{array}$ & $\begin{array}{c}P=0.20 \\
1.60 \\
(0.78-3.28)\end{array}$ \\
\hline
\end{tabular}

${ }^{a}$ Correlation was analyzed by Fisher's exact test

${ }^{\mathrm{b}} \mathrm{OR}$, Odds ratio. ORs were adjusted for age and sex

c $95 \%$ CI, 95\% confidence interval

dTumor grade was classified according to the criteria of the UICC TNM stage grouping. Histology was classified according to the criteria of Lauren

nostic significance must be clarified. It should be mentioned that controversial observations have been reported in regard to the association between E-cadherin SNP and gastric cancer $[53,54]$.

\section{Novel prognostic factors identified by gene expression profiles}

A genome-wide study of a gene expression profile is of great advantage to uncover the precise mechanism of the development and progression of cancer and to identify novel biomarkers of malignancy that could be candidate prognostic factors.

\section{Serial analysis of gene expression (SAGE)}

SAGE is a powerful technique that allows the global analysis of gene expression in a quantitative manner, without prior knowledge of the sequence of the genes $[55,56]$. Among the four SAGE studies of gastric cancer reported [57-60], ours [60] has described the largest SAGE libraries of gastric cancer in the world, and sequence data are publicly available at SAGEmap (Gene Expression Omnibus [GEO] accession number GSE 545, SAGE Hiroshima gastric cancer tissue). By comparing gene expression profiles between gastric cancer and normal gastric mucosa, in combination with quantitative reverse transcription-polymerase chain reaction (RT-PCR), COL1A1, CDH17, APOC1, COL1A2,
YF13H12, CEACAM6, APOE, REGIV, S100A11, and FUS were found to be overexpressed in over $40 \%$ of gastric cancers [60]. Candidate genes involved in invasion and metastasis can be identified by comparing SAGE libraries between early cancer and advanced cancer or between primary tumor and metastatic tumor. Quantitative real-time RT-PCR confirmed that the expression of CDH17, APOE, FUS, COL1A1, and $C O L 1 A 2$ was associated with tumor invasion, metastasis, and stage grouping, indicating that these could be novel genetic markers for high-grade malignancy. In fact, the prognosis of CDH17-positive patients is significantly worse than that of -negative patients [56].

If a gene participates in tumor progression and is specifically expressed in cancer but not in normal tissues, the gene can be not only a cancer biomarker but also a therapeutic target, with minimal adverse effects [56]. By comparing SAGE libraries of gastric cancer with those of various normal tissues in the SAGEmap database, we identified about 60 genes that were detected in our gastric cancer libraries, but not in the libraries from 12 normal tissues, including brain, lung, heart, liver, and kidney. We then validated the expression of these genes in gastric cancers and normal human tissues by quantitative RT-PCR and found that 8 genes, including MIA (melanoma inhibitory activity) and $G W 112$, were specifically expressed in gastric cancer (Fig. 2). MIA was first isolated as a secreted protein from malignant melanoma cell lines [61]. MIA enhances migration and invasion ability and inhibits apoptosis; 


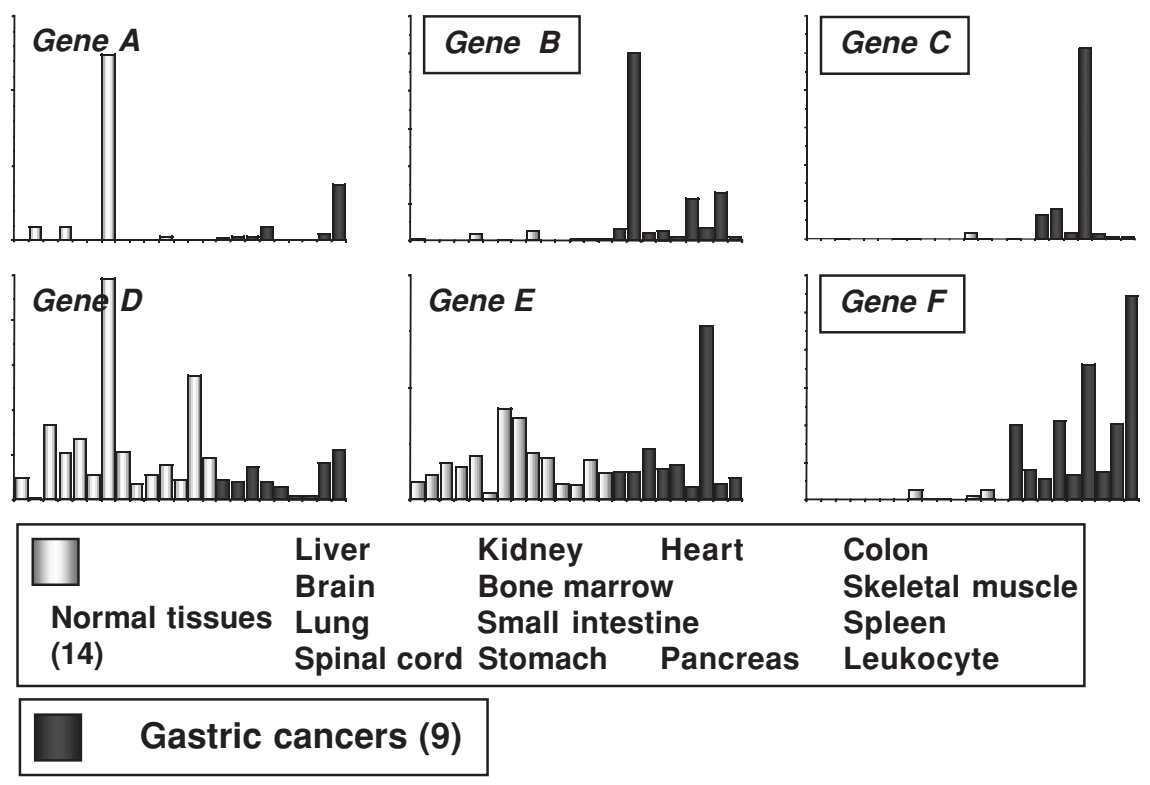

Fig. 2. Quantitative reverse transcription-polymerase chain reaction (RTPCR) of various normal tissues and gastric cancers. The expression of genes $B, C$, and $F$ is confined to gastric cancers, while that of genes $A, D$, and $E$ is detected in both normal tissues and gastric cancers at various levels increased serum levels of MIA are correlated with the progression of melanoma [62,63]. The expression levels of $M I A$ were correlated with advanced tumor stage of gastric cancer. Immunostaining of MIA demonstrated a significant association with tumor stage in gastric cancer patients, and high levels of MIA were detected in the sera of stage IV patients by enzyme-linked immunosorbent assay (ELISA). Patients with MIA-positive cancer showed poorer prognoses than those with MIAnegative cancer. This approach provides a list of candidate genes that may serve not only as prognostic factors but also as good therapeutic targets of gastric cancer.

\section{Microarray-based molecular and genetic analysis}

Several microarray studies have been performed in gastric cancer to find gene expression signatures specifically related to metastasis and prognosis. Hippo et al. [64] studied the expression profiles of 6800 genes and reported that overexpression of RBP4, OCT2, IGF2, PFN2, KIAA1093, PCOLCE, and FN1 was associated with lymph-node metastasis. Hasegawa et al. [65] performed a genome-wide analysis of gene expression in well-differentiated gastric cancer, using a cDNA microarray representing 23040 genes, and found that the altered expression of 12 genes (DDOST, GNS, NEDD8, LOC51096, CCT3, CCT5, PPP2R1B, $U B Q L N 1, A I M 2, U S P 9 X$, and two expressed sequence tags [ESTs]) was associated with lymph-node metastasis. Inoue et al. [66] developed a prognostic scoring system using a cDNA microarray. Seventy-eight genes (including MMP-7, SPARC, TGFB3, THBS2, PCNA, CEACAM6, FN1, IGFBP3, and CSPG2) were dif- ferentially expressed in patients with aggressive and nonaggressive gastric cancers. The prognostic score, calculated by summing-up the value of a coefficient for each gene, can predict the stage of disease and the patient's prognosis. We have developed a custom-made oligo-DNA microarray including specific genes identified by our SAGE analysis, known genes related to the development and progression of cancer, and marker genes for chemosensitivity [56]. We were able to identify clusters of genes that differentiated stage grouping (Fig. 3). These lines of evidence indicate that microarray analysis is useful to search for novel prognostic factors, and it also has great potential for identifying the characteristics of individual cancers from the viewpoint of gene expression profiles.

Array-based technology can be applicable to the study of chromosomal aberrations related to tumor progression and prognosis. Microarray comparative genomic hybridization demonstrates the genomic profiling of gastric cancer, and chromosomal copy number changes predict metastatic status and survival [67]. Gain of 1q32.3 is significantly correlated with lymph-node status, while tumors with loss of $18 \mathrm{q} 22.1$, as well as tumors with amplifications, are associated with poor prognosis of the patients.

\section{Application of novel prognostic markers in molecular diagnosis}

Figure 4 illustrates a strategy for the molecular diagnosis of gastric cancer in pathology samples [56]. The expression of novel prognostic factors can be examined 


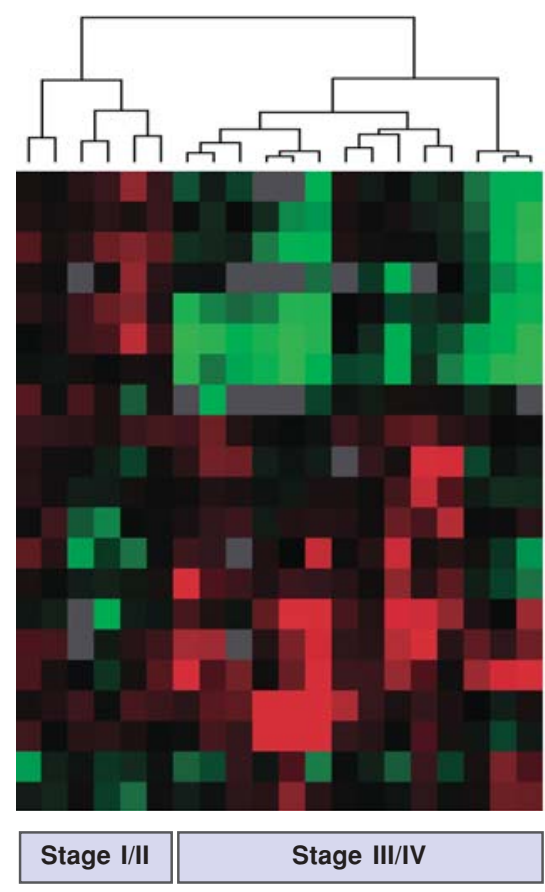

Up-regulated

Down-regulated

Known genes related to cancer

Marker genes for malignancy and chemosensitivity

Specific genes identified by SAGE analysis

Known genes related to cancer

Known genes related to cancer

Known genes related to cancer

Known genes related to cancer

Known genes related to cancer

Marker genes for malignancy and chemosensitivity

Specific genes identified by SAGE analysis

Specific genes identified by SAGE analysis

Known genes related to cancer

Marker genes for malignancy and chemosensitivity

Specific genes identified by SAGE analysis

Specific genes identified by SAGE analysis

Known genes related to cancer

Specific genes identified by SAGE analysis

Specific genes identified by SAGE analysis

Known genes related to cancer

Marker genes for malignancy and chemosensitivity

Known genes related to cancer
Fig. 3. Hierarchical clustering analysis of gene expression profiles by tumor stage. Gene expression profiles were examined in 20 surgically resected gastric cancer tissues after T7-based RNA amplification, using a mixture of normal gastric mucosal tissues as a reference. Twentyone genes showing significant correlation with stage grouping were selected, using one-way analysis of variance (ANOVA; $P<0.05$ ) by GeneSpring (Silicon Genetics, Redwood, CA, USA), and hierarchical clustering was performed. SAGE, Serial analysis of gene expression

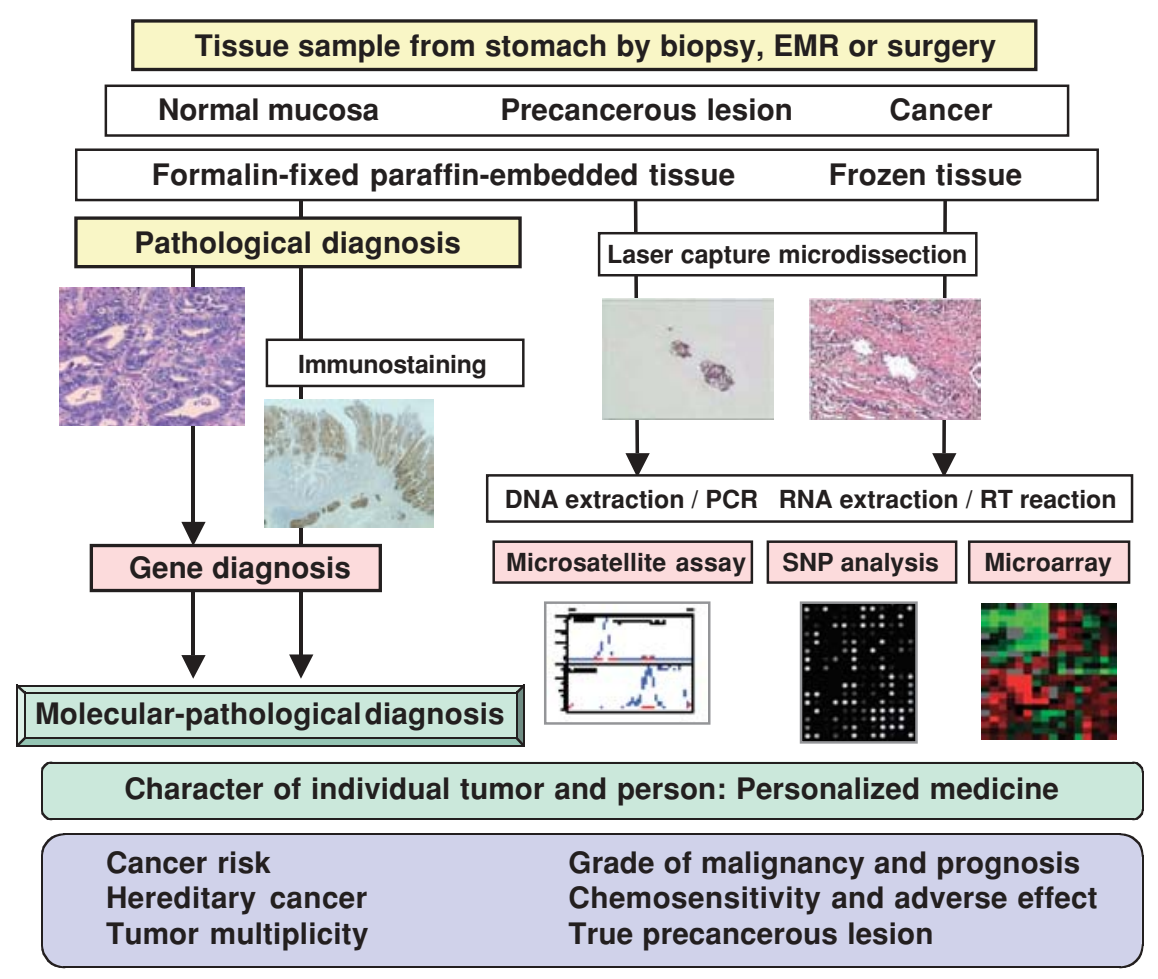

Fig. 4. Strategy for the molecularpathological diagnosis of gastric cancer using tissue samples. EMR, endoscopic mucosal resection; SNP, singlenucleotide polymorphism immunohistochemically if antibodies are available. A system for detection in blood samples can be established using the antibodies. From tissues samples, either freshly frozen or fixed with formalin and embedded in paraffin, RNA or DNA is extracted. The gene expres- sion profile, obtained with a custom-made microarray, gives information on the grade of malignancy/prognosis and chemosensitivity/adverse effects. Microsatellite analysis predicts tumor multiplicity. Analysis of genetic polymorphisms will give information on cancer risk and 
sensitivity to chemotherapy, and predict the biological behavior of the cancer. A combination of these examinations can not only foretell the patient's prognosis but can also clarify the characteristics of the individual tumor and person, which are directly connected with genomic medicine; namely, personalized medicine and cancer prevention.

\section{References}

1. Tahara E. Molecular mechanism of stomach carcinogenesis. J Cancer Res Clin Oncol 1993;119:265-72.

2. Yasui W, Oue N, Kuniyasu H, Ito R, Tahara E, Yokozaki H. Molecular diagnosis of gastric cancer: present and future. Gastric Cancer 2001;4:113-21.

3. Ohgaki H, Yasui W, Yokota J. Genetic pathway to human cancer. In: Vainio H, Hietanen E, editors. Handbook of experimental pharmacology. Mechanisms in carcinogenesis and cancer research. Berlin Heidelberg New York Singapore Tokyo: SpringerVerlag; 2003. p. 25-39.

4. Yokozaki H, Yasui W, Tahara E. Genetic and epigenetic changes in stomach cancer. Int Rev Cytol 2001;204:49-95.

5. Yasui W, Oue N, Ono S, Mitani Y, Ito R, Nakayama H. Histone acetylation and gastrointestinal carcinogenesis. Ann NY Acad Sci 2003;983:220-31.

6. Fidler IJ. Critical determinants of human colon cancer metastasis. In: Tahara E, editor. Molecular pathology of gastroenterological cancer. Berlin Heidelberg Now York Singapore Tokyo: SpringerVerlag; 1997. p. 147-69.

7. Werner M, Becker KF, Hofler H. Gastric adenocarcinoma: pathomorphology and molecular pathology. J Cancer Res Clin Oncol 2001;127:207-16.

8. Takahashi Y, Cleary KR, Mai M, Kitadai Y, Bucana CD, Ellis LM. Significance of vessel count and vascular endothelial growth factor and its receptor (KDR) in intestinal-type gastric cancer. Clin Cancer Res 1996;2:1679-84.

9. Kitadai Y, Haruma K, Sumii K, Yamamoto S, Ue T, Yokozaki H, et al. Expression of IL-8 correlates with vascularity in human gastric carcinomas. Am J Pathol 1998;152:93-100.

10. Takahashi Y, Bucana CD, Akagi Y, Liu W, Cleary KR, Mai M, et al. Significance of platelet-derived endothelial cell growth factor in the angiogenesis of human gastric cancer. Clin Cancer Res 1998;4:429-34.

11. Kido S, Kitadai Y, Hattori N, Haruma K, Kido T, Ohta M, et al. Interleukin 8 and vascular endothelial growth factor - prognostic factors in human gastric carcinoma? Eur J Cancer 2001;37:1482-7.

12. Yasui W, Yokozaki H, Shimamoto F, Tahara H, Tahara E. Molecular-pathological diagnosis of gastrointestinal tissues and its contribution to cancer histopathology. Pathol Int 1999;49:76374.

13. Xiangming C, Natsugoe S, Takao S, Hokita S, Tanabe G, Baba M, et al. The cooperative role of $\mathrm{p} 27$ and cyclin $\mathrm{E}$ in the prognosis of advanced gastric carcinoma. Cancer 2000;89:1214-9.

14. Tsujie M, Yamamoto H, Tomita N, Sugita Y, Ohue M, Sakita I, et al. Expression of tumor supressor gene p16 (INK4) products in primary gastric cancer. Oncology 2000;58:126-36.

15. Feakins RM, Nickols CD, Bidd H, Walton SJ. Abnormal expression of pRb, p16, and cyclin D1 in gastric adenocarcinoma and its lymph node metastases: relationship with pathological features and survival. Hum Pathol 2003;34:1276-82.

16. Fondevila C, Metges JP, Fuster J, Grau JJ, Palacin A, Castells A, et al. p53 and VEGF expression are independent predictors of tumor recurrence and survival following curative resection of gastric cancer. Br J Cancer 2004;90:206-15.

17. Pinto-de-Sousa J, Silva F, David L, Leitao D, Seixas M, Pimenta A, et al. Clinicopathological significance and survival influence of p53 protein expression in gastric carcinoma. Histopathology 2004;44:323-31.

18. Horii A, Han HJ, Shimada M, Yanagisawa A, Kato Y, Yasui W, et al. Freauent replication errors at microsatellite foci in tumors of patients with multiple primary cancers. Cancer Res 1994;56:66874.

19. Nakashima H, Honda M, Inoue H, Shibuta K, Arinaga S, Era S, et al. Microsatellite instability in multiple gastric cancers. Int $\mathbf{J}$ Cancer 1995;64:239-42.

20. Takahashi H, Endo T, Yamashita K, Arimura Y, Yamamoto H, Sasaki S, et al. Mucin phenotype and microsatellite instability in early multiple gastric cancers. Int J Cancer 2002;100:419-24.

21. Dos Santos NR, Seruca R, Constancia M, Seixas M, SobrinhoSimoes M. Microsatellite instability at multiple loci in gastric carcinoma: clinicopathologic implications and prognosis. Gastroenterology 1996;110:38-44.

22. Iacopetta BJ, Soong R, House AK, Hamelin R. Gastric carcinomas with microsatellite instability: clinical features and mutations to the TGF-beta type II receptor, IGFII receptor, and $B A X$ genes. J Pathol 1999;187:428-32.

23. Wirtz HC, Muller W, Noguchi T, Scheven M, Ruschoff J, Hommel G, et al. Prognostic value and clinicopathological profile of microsatellite instability of gastric cancer. Clin Cancer Res 1998;4:1749-54.

24. Choi SW, Choi JR, Chung YJ, Kim KM, Rhyu MG. Prognostic implications of microsatellite genotypes in gastric carcinomas. Int J Cancer 2000;89:378-83.

25. Kim NW, Piatyszek MA, Prowse KR, Harley CB, West MD, Ho PL, et al. Specific association of human telomerase activity with immortal cells and cancer. Science 1994;266:2011-5.

26. Yasui W, Tahara E, Tahara H, Fujimoto J, Naka K, Nakayama J, et al. Immunohistochemical detection of human telomerase reverse transcriptase in normal and precancerous lesions of the stomach. Jpn J Cancer Res 1999;90:589-95.

27. Kondo T, Oue N, Yoshida K, Mitani Y, Naka K, Nakayama H, et al. Expression of POT1 is associated with tumor stage and telomere length in gastric carcinoma. Cancer Res 2004;64:5239.

28. Shimada Y, Yamasaki S, Hashimoto Y, Ito T, Kawamura J, Soma $\mathrm{T}$, et al. Clinical significance of dysadherin expression in gastric cancer patients. Clin Cancer Res 2004;10:2818-23

29. Chan AO, Lam SK, Chu KM, Lam CM, Kwok E, Leung SY, et al. Soluble E-cadherin is a valid prognostic marker in gastric carcinoma. Gut 2001;48:808-11.

30. Yamauchi K, Uehara Y, Kitamura N, Nakane Y, Hioki K. Increased expression of CD44v6 mRNA significantly correlates with distant metastasis and prognosis in gastric cancer. Int $\mathbf{J}$ Cancer 1998;79:256-62.

31. Saito H, Tsujitani S, Katano K, Ikeguchi M, Maeta M, Kaibara N. Serum concentration of CD44 variant 6 and its relation to prognosis in patients with gastric carcinoma. Cancer 1998;83:1094-101.

32. Mayer B, Jauch KW, Gunthert U, Figdor CG, Schildberg FW, Funke I, et al. De-novo expression of CD44 and survival in gastric cancer. Lancet 1993;342:1019-22.

33. Yamashita K, Azumano I, Mai M, Okada Y. Expression and tissue localization of matrix metalloproteinase 7 (matrilysin) in human gastric carcinomas. Implications for vessel invasion and metastasis. Int J Cancer 1998;79:187-94.

34. Inoue T, Yashiro M, Nishimura S, Maeda K, Sawada T, Ogawa Y, et al. Matrix metalloproteinase-1 expression is a prognostic factor for patients with advanced gastric cancer. Int J Mol Med 1999; 4:73-7.

35. Mori M, Mimori K, Shiraishi T, Fujie T, Baba K, Kusumoto H, et al. Analysis of MT1-MMP and MMP2 expression in human gastric cancers. Int J Cancer 1997;74:316-21.

36. Mimori K, Mori M, Shiraishi T, Fujie T, Baba K, Haraguchi M, et al. Clinical significance of tissue inhibitor of metalloproteinase expression in gastric carcinoma. Br J Cancer 1997;76:531-6.

37. Mitani Y, Oue N, Hamai Y, Aung PP, Matsumura S, Nakayama $\mathrm{H}$, et al. Histone $\mathrm{H} 3$ acetylation is associated with reduced 
p21 ${ }^{\text {WAFI/CIP1 }}$ expression in gastric carcinoma. J Pathol 2005;205:6573.

38. Suzuki T, Kuniyasu H, Hayashi K, Naka K, Yokozaki H, Ono S, et al. Effect of trichostatin A on cell growth and expression of cell cycle- and apoptosis-related molecules in human gastric and oral carcinoma cell lines. Int J Cancer 2000;88:992-7.

39. Oue N, Motoshita J, Yokozaki H, Hayashi K, Tahara E, Taniyama K, et al. Distinct promoter hypermethylation of p16ink4a, CDH1, and RAR-beta in intestinal, diffuse-adherent, and diffuse-scattered type gastric carcinoma. J Pathol 2002;198: 55-9.

40. Oshimo Y, Oue N, Mitani Y, Nakayama H, Kitadai Y, Yoshida K, et al. Frequent loss of RUNX3 expression by promoter hypermethylation in gastric carcinoma. Pathobiology 2004;71: 137-43.

41. Oue N, Shigeishi H, Kuniyasu H, Yokozaki H, Kuraoka K, Ito R, et al. Promoter methylation of MGMT is associated with protein loss in gastric carcinomas. Int J Cancer 2001;93:805-9.

42. Oue N, Matsumura S, Nakayama H, Kitadai Y, Taniyama K, Matsusaki K, et al. Expression of the TSP-1 gene and its association with promoter hypermethylation in gastric carcinomas. Oncology 2003;64:423-9.

43. Hamai Y, Oue N, Mitani Y, Nakayama H, Ito R, Matsusaki K, et al. DNA methylation and histone acetylation status of $H L T F$ gene are associated with reduced expression in gastric carcinoma. Cancer Sci 2003;94:692-8.

44. Oshimo Y, Oue N, Mitani Y, Nakayama H, Kitadai Y, Yoshida K, et al. Frequent epigenetic inactivation of RIZ1 by promoter hypermethylation in human gastric carcinoma. Int $\mathrm{J}$ Cancer 2004;110:212-8.

45. Oshimo Y, Kuraoka K, Nakayama H, Kitadai Y, Yoshida K, Chayama K, et al. Epigenetic inactivation of SOCS-1 by CpG island hypermethylation in human gastric carcinoma. Int J Cancer 2004:112:212-8.

46. Toyota M, Ahuja N, Suzuki H, Itoh F, Ohe-Toyota M, Imai K, et al. Aberrant methylation in gastric cancer associated with the CpG island methylator phenotype. Cancer Res 1999;59:5438-42.

47. Gonzalez CA, Sala N, Capella G. Genetic susceptibility and gastric cancer risk. Int J Cancer 2002;100:249-60.

48. Kuraoka K, Oue N, Matsumura S, Hamai Y, Ito R, Nakayama H, et al. A single nucleotide polymorphism in the transmembrane domain coding region of HER-2 is associated with development and malignant phenotype of gastric cancer. Int J Cancer 2003; 107:593-6.

49. Hamai Y, Matsumura S, Kuraoka K, Matsusaki K, Kitadai Y, Yoshida K, et al. A single nucleotide polymorphism in the $5^{\prime}$ untranslated region of $E G F$ gene is associated with occurrence and malignant progression of gastric cancer. Pathobiology 2005; (in press).

50. Kuraoka K, Oue N, Yokozaki H, Kitadai Y, Ito R, Nakayama H, et al. Correlation of a single nucleotide polymorphism in the Ecadherin gene promoter with tumorigenesis and progression of gastric carcinoma in Japan. Int J Oncol 2003;23:421-7.

51. Matsumura S, Oue N, Kitadai Y, Chayama K, Yoshida K, Yamaguchi $\mathrm{Y}$, et al. A single nucleotide polymorphism in the MMP-1 promoter is correlated with histological differentiation of gastric cancer. J Cancer Res Clin Oncol 2004;130:259-65.
52. Matsumura S, Oue N, Nakayama H, Kitadai Y, Yoshida K, Yamaguchi $\mathrm{Y}$, et al. A single nucleotide polymorphism of the MMP9 promoter affects tumor progression and invasive phenotype of gastric cancer. J Cancer Res Clin Oncol 2005;131:19-25.

53. Wu MS, Huang SP, Chang YT, Lin MT, Shun CT, Chang MC, et al. Association of the $-160 \mathrm{C} \rightarrow$ A promoter polymorphism of the E-cadherin gene with gastric carcinoma risk. Cancer 2002; 94:1443-8.

54. Pharoah PD, Oliveira C, Machado JC, Keller G, Vogelsang H, Laux H, et al. CDH1 c-160a promoter polymorphism is not associated with risk of stomach cancer. Int J Cancer 2002;101:1967.

55. Velculescu VE, Zhang L, Vogelstein B, Kinzler KW. Serial analysis of gene expression. Science 1995;270:484-7.

56. Yasui W, Oue N, Ito R, Kuraoka K, Nakayama H. Search for new biomarkers of gastric cancer through serial analysis of gene expression and its clinical implications. Cancer Sci 2004;95:38592.

57. El-Rifai W, Moskaluk CA, Abdrabbo MK, Harper J, Yoshida C, Riggins GJ, et al. Gastric cancers overexpress S100A calciumbinding proteins. Cancer Res 2002;62:6823-6.

58. Oien KA, Vass JK, Downie I, Fullarton G, Keith WN. Profiling, comparison and validation of gene expression in gastric carcinoma and normal stomach. Oncogene 2003;22:4287-300.

59. Lee JY, Eom EM, Kim DS, Ha-Lee YM, Lee DH. Analysis of gene expression profiles of gastric normal and cancer tissues by SAGE. Genomics 2003;82:78-85.

60. Oue N, Hamai Y, Mitani Y, Matsumura S, Oshimo Y, Aung PP, et al. Gene expression profile of gastric carcinoma; identification of genes and tags potentially involved in invasion, metastasis, and carcinogenesis by serial analysis of gene expression. Cancer Res 2004:64:2397-405.

61. Blesch A, Bosserhoff AK, Apfel R, Behl C, Hessdoerfer B, Schmitt A, et al. Cloning of a novel malignant melanoma-derived growth-regulatory protein, MIA. Cancer Res 1994;54:5695-701.

62. Bosserhoff AK, Kaufmann M, Kaluza B, Bartke I, Zirngibl H, Hein R, et al. Melanoma-inhibiting activity, a novel serum marker for progression of malignant melanoma. Cancer Res 1997;57: 3149-53.

63. Poser I, Tatzel J, Kuphal S, Bosserhoff AK. Functional role of MIA in melanocytes and early development of melanoma. Oncogene 2004;23:6115-24.

64. Hippo Y, Taniguchi H, Tsutsumi S, Machida N, Chong JM, Fukayama M, et al. Global gene expression analysis of gastric cancer by oligonucleotide microarrays. Cancer Res 2002;62:23340.

65. Hasegawa S, Furukawa Y, Li M, Satoh S, Kato T, Watanabe T, et al. Genome-wide analysis of gene expression in intestinal-type gastric cancers using a complementary DNA microarray representing 23040 genes. Cancer Res 2002;62:7012-7.

66. Inoue H, Matsuyama A, Mimori K, Ueo H, Mori M. Prognostic score of gastric cancer determined by cDNA microarray. Clin Cancer Res 2002;8:3475-9.

67. Weiss MM, Kuipers EJ, Postma C, Snijers AM, Pinkel D, Meuwissen SG. Genomic alterations in primary gastric adenocarcinomas correlate with clinicopathological characteristics and survival. Cell Oncol 2004;26:307-17. 